\title{
What Can We Learn from the Spanish Flu Pandemic of 1918-19 for COVID-19?
}

\author{
David C. Wheelock, Group Vice President and Deputy Director of Research
}

$\mathrm{T}$ he COVID-19 pandemic has spurred intense efforts among researchers to estimate the likely course of the pandemic and its economic effects. Several studies have sought insights from global pandemics of the past, including the Spanish flu pandemic of 1918-19, which is thought to have infected some 500 million persons, or about one-third of the world's population, and killed anywhere from 50 to 100 million people. ${ }^{1}$ Lessons from the Spanish flu pandemic are relevant and informative. Like COVID-19, the Spanish flu was highly contagious; it was also unusually lethal compared with a typical seasonal flu. As the flu became more widespread and its dangers apparent, many cities sought to contain the virus by imposing restrictions on social and economic interactions. These efforts can provide insights about the economic and public health impacts of government efforts to limit the spread of pandemic diseases. This essay discusses some recent research findings on the effects of the Spanish flu pandemic and measures that cities took to control it.

The Spanish flu pandemic came in three waves beginning in the spring of 1918. The second wave, in the fall of 1918, was the largest by far in terms of total infections and deaths. A third wave occurred in the spring of 1919. Overall, the pandemic is estimated to have infected about 25 percent of the U.S. population, or about 25 million people, and killed 675,000 for roughly a 3 percent mortality rate. ${ }^{2}$ The pandemic began during World War I, and the virus is thought to have been introduced and spread throughout the United States by soldiers returning from Europe. By the end of 1918, some 45,000 U.S. soldiers had contracted and died from the disease, a number only modestly smaller than the 53,000 American combat deaths. ${ }^{3}$ As with typical seasonal flu, young children and the elderly were particularly susceptible to the Spanish flu. However, the Spanish flu was especially lethal for young, "prime-age" adults, especially men. In 1918, the mortality rate from the flu and pneumonia among men 15 to 34 years of age was more than 20 times higher than in previous years, and throughout the pandemic, half of all flu deaths were among adults between 20 and 40 years of age. Furthermore, the absolute risk of death from the flu was higher among those younger than 65 years of age than those 65 or older, with those younger than 65 accounting for 99 percent of excess flu deaths in 1918-19.4 The high fatality rate among young adults, especially young adult men, is striking in comparison with both typical seasonal flu and COVID-19, where the case fatality rate has been far higher among the elderly than among the young. These differences in age-related fatality rates are one reason the economic impacts of the COVID-19 and Spanish flu pandemics might differ. The high fatality rate among prime-age males during the Spanish flu pandemic reduced labor supply and boosted real wage rates in locations where the incidence of the disease was high (Garret, 2009, and Correia et al., 2020). Such an effect seems unlikely from the COVID-19 pandemic. ${ }^{5}$

As the COVID-19 pandemic spread across the United States, most state and local governments imposed restrictions on economic activity, such as requiring certain nonessential businesses to close or reduce their in-store services. Many firms have voluntarily reduced their operations to protect the health of their employees or because of weaker demand for their products. At the same time, many households have refrained from non-essential purchases and travel in an effort to protect themselves and to help limit the spread of the virus. To date these measures appear to have helped slow the pandemic and avoid overwhelming the health care system in most locations. However, aggregate economic activity and employment have declined sharply, leading many states and cities to ease restrictions even as COVID-19 cases and fatalities continue to rise.

A similar pattern played out during the Spanish flu pandemic. In an effort to stem the pandemic, many cities adopted measures such as closing schools and churches, prohibiting large gatherings of people, shutting down theaters and other entertainment venues, and temporarily closing non-essential businesses. ${ }^{6}$ Several studies examine the effects of such non-pharmaceutical interventions (NPIs) on flu incidence and mortality rates. A general finding is that cities that put NPIs in place earlier or took more aggressive action had lower excess mortality rates, later peaks in 
caseloads and mortality, and, to a lesser extent, fewer total fatalities than cities that moved slowly or adopted fewer measures. ${ }^{7}$ The experiences of Philadelphia and St. Louis are often compared. Philadelphia was slow to implement measures to stem the pandemic and experienced a surge in cases following a large parade in support of a Liberty Loan drive. St. Louis, by contrast, canceled a similar parade and took other measures soon after the first cases were reported. Philadelphia had among the highest mortality rates of any of the U.S. cities, with a peak weekly excess mortality rate of 250 deaths per 100,000 persons and a total pandemic mortality rate of 748 deaths per 100,000 persons. St. Louis had among the lowest rates of all major cities, with a peak weekly excess mortality rate of just 30 deaths per 100,000 persons and a total mortality rate of 358 deaths per 100,000 persons (Markel et al., 2007).

As the Spanish flu became more widespread and its dangers apparent, many cities sought to contain the virus by imposing restrictions on social and economic interactions.

Most cities relaxed their measures after just a few weeks when flu deaths began to recede. However, many cities faced a surge in cases when measures were eased, which resulted in a second peak-often higher than the first-that led to reactivation of some NPIs (Bootsma and Ferguson, 2007, and Markel et al., 2007). The experience of St. Louis is a case in point. St. Louis's authorities moved quickly to close schools, churches, saloons, theaters, and other entertainment venues when the city's first cases appeared in early October. Businesses and factories were permitted to remain open, but business hours were reduced and police were dispatched to keep shoppers from lingering in stores. On November 9, the health commissioner ordered all nonessential stores and factories closed for four days, and cases peaked within days. Businesses were permitted to reopen on November 13 and schools opened on November 14 . Flu cases continued to decline for the next two weeks but then began to climb sharply. The city closed schools again and reinstated a ban on all public gatherings. The second peak in cases-with a higher excess mortality rate than the first peak-was reached in December. Cases then began to decline and the city lifted all restrictions on businesses on December 28 and reopened schools on January 2.8

The economic impacts of the flu pandemic and NPIs implemented to contain it are somewhat less clear than the epidemiological effects. Perhaps surprisingly, given the widespread incidence of illness and many deaths, the pandemic did not trigger a major contraction in aggregate economic activity. A mild recession began in September 1918 and continued to March 1919. Federal spending on the war effort might explain why the aggregate economy did not slow appreciably: "[T] he never-ending demand for coal, steel, machinery, textiles, and other products needed for the war effort largely offset the effects of such a severe pandemic on aggregate economic activity" (Benmelech and Frydman, 2020). Industrial production did fall sharply but recovered quickly. Retail sales appear to have been little affected by the pandemic, perhaps because of a surge in consumer purchases after Armistice on November 11, and neither business failures nor other forms of financial distress increased significantly. ${ }^{9}$ The pandemic did have a large impact on some sectors, however-notably manufacturing. Correia et al. (2020) estimate that the pandemic caused an 18 percent decline in manufacturing output and a 23 percent decline in manufacturing employment, in part because several cities with large manufacturing industries were among those with the highest flu fatality rates.

Some NPIs, such as temporary closures of non-essential businesses, clearly impose direct economic costs on affected firms and households. However, widespread illness or deaths can also be economically costly, suggesting that, conceivably, the economic benefits of containing a pandemic might outweigh the direct costs imposed on owners and employees of firms that are required to close. During the Spanish flu pandemic, cities with lower excess flu mortality rates had smaller declines in some measures of economic activity, suggesting that the direct cost of NPIs might have been offset at least to some extent by stronger economies. Moreover, there is evidence that cities that imposed NPIs earlier and more rigorously during the pandemic had higher growth in manufacturing output and employment for up to four years after the pandemic. Correia et al. (2020) use a dynamic difference-in-difference regression approach to examine the impact of NPIs on manufacturing across cities. Their model controls for various pre-crisis state and local characteristics, such as total population, urbanization, manufacturing share of employment, and growth of manufacturing output and employment from 1909 to 1914. The study finds that implementing NPIs earlier in the pandemic and using them more intensely produced significantly higher rates of growth in manufacturing output and employment from 1919 to 1923 than did slower activation or less intense use of NPIs. Estimates from the study's base model indicate that a one standard deviation increase in the speed of adopting NPIs (8 days) is associated with 4 percent 
higher growth of employment after the pandemic, while a one standard deviation increase in NPI intensity leads to 6 percent higher employment growth. The authors estimate several models with different sets of controls, and though not all show a statistically significant impact of NPIs on growth or employment, none indicate that NPIs reduced economic activity. ${ }^{10}$

Clearly, there are limits to the applicability of the Spanish flu episode to the COVID-19 pandemic. In particular, the unusually high fatality rate among young, working-age men suggests that the flu pandemic might have had a larger economic impact, particularly on labor-intensive industries, than will COVID-19. The structure of the U.S. economy and distribution of the population are also very different today than in 1918, which could affect how either a pandemic or the NPIs imposed to contain it affect public health or the economy. For example, because pandemic mortality is strongly associated with population density, increased urbanization suggests that NPIs might have more public health benefit today than in 1918. On the other hand, the substantial increase over time in employment in the service sector suggests that the direct costs of mandatory business closures, which tend to fall more heavily on retail establishments and other service industries, could be higher today than in 1918. ${ }^{11}$ Still, insights from the Spanish flu and other pandemics should not be dismissed entirely. So long as we remain cognizant of the environmental features in which they occurred, the pandemics of the past can provide useful data points for helping to forecast how the COVID-19 and future pandemics are likely to play out, and in particular for addressing such questions as whether NPIs are likely to be the sole source of economic disruptions in a pandemic, or whether a pandemic would cause an economic downturn in the absence of interventions to slow its spread.

\section{Notes}

1 Johnson and Mueller (2002) estimate 50 million deaths worldwide and provide estimates for several countries. Jorda et al. (2020) report an estimate of 100 million deaths, as well as mortality estimates for other pandemics since the fourteenth century with at least 100,000 deaths.

2 Taubenberger and Morens (2006). See also Garrett (2008) and references therein for data and other information about the origins and spread of the pandemic in the United States.

3 Eric Durr, "Worldwide Flu Outbreak Killed 45,000 American Soldiers During World War I"; https://www.army.mil/article/210420/worldwide_flu_outbreak killed_45000_american_soldiers_during_world_war_i.

4 Taubenberger and Morens (2006).

5 In a study of 15 major pandemics since the fourteenth century, Jorda, Singh, and Taylor (2020) find that real wages are typically elevated for several years after pandemics, while the returns to capital are low, likely because of widespread deaths among the working-age population.
${ }^{6}$ Detailed information about the use of NPIs by 50 cities during the pandemic is available from the University of Michigan Center for the History of Medicine; http://chm.med.umich.edu/research/1918-influenza-digital-archive/.

7 See Barro (2020), Correia et al. (2020), Bootsma and Ferguson (2007), Hatchett et al. (2007), and Markel et al. (2007). Barro (2020) notes that the mean duration of NPIs across 43 cities was 4-6 weeks and suggests that a duration of 12 weeks would have produced a substantially lower total death rate.

8 University of Michigan Center for the History of Medicine; https://www.influenzaarchive.org/cities/city-stlouis.html.

9 Velde (2020) examines a variety of high-frequency economic time series data during the pandemic and concludes that the pandemic had only modest impact on economic activity. Barro et al. (2020) examine the impact of the pandemic across countries and attempt to control for differences in war intensity using data on combat deaths. The study finds that the flu pandemic caused a 6.2 percent decline in GDP in a typical country and a decline of about 1.5 percent in the United States.

10 The base specification controls include measures of urbanization, pre-crisis population, manufacturing employment share, and flu mortality in 1917, as well as state-level agricultural employment share. Additional control variables in other specifications include the growth in manufacturing output and employment from 1909 to 1914, census region fixed effects, longitude, WWI servicemen mortality rate, and health and total public spending per capita in 1917.

11 In 1918, the U.S. population was split evenly between urban and rural areas in 1918, whereas today the urban population is five times the rural population. Moreover, in 1918, 33 percent of the labor force was employed in agriculture and 28 percent was employed in manufacturing, compared with 2 percent and 8 percent, respectively, today (Velde 2020). As of 2018, some 80 percent of the U.S. labor force was employed in service industries. See https://www.bls.gov/emp/tables/employment-by-major-industry-sector.htm.

\section{References}

Barro, Robert J. "Non-Pharmaceutical Interventions and Mortality in U.S. Cities During the Great Influenza Pandemic, 1918-1919." NBER Working Paper 27049, April 2020.

Barro, Robert J.; Ursua, Jose F. and Weng, Joanna. "The Coronavirus and the Great Influenza Pandemic - Lessons from the 'Spanish Flu' for the Coronavirus's Potential Effects on Mortality and Economic Activity." NBER Working Paper 26866, March 2020.

Benmelech, Efraim and Frydman, Carola. "The 1918 Influenza Did Not Kill the US Economy." VOX CEPR Policy Portal, April 29, 2020.

Bootsma, Martin C.J. and Ferguson, Neil M. "The Effect of Public Health Measures on the 1918 Influenza Pandemic in U.S. Cities." Proceedings of the National Academy of Sciences, May 2007, 104(18), pp. 7588-93.

Correia, Sergio; Luck, Stephan and Verner, Emil. "Pandemics Depress the Economy, Public Heath Interventions Do Not: Evidence from the 1918 Flu." SSRN Working Paper No. 3561560, April 10, 2020.

Garrett, Thomas A. "Pandemic Economics: The 1918 Influenza and Its ModernDay Implications." Federal Reserve Bank of St. Louis Review, March/April 2008, pp. 75-93.

Garrett, Thomas A. "War and Pestilence as Labor Market Shocks: U.S. Manufacturing Wage Growth 1914-1919." Economic Inquiry, October 2009, 47(4), pp. 711-25.

Hatchett, Richard J.; Mecher, Carter E. and Lipsitch, Marc. "Public Health Interventions and Epidemic Intensity during the 1918 Influenza Pandemic." Proceedings of the National Academy of Sciences, May 2007, 104(18), pp. 7582-87. 


\section{ECONOMIC Synopses}

Johnson, Niall P.A.S. and Mueller, Juergen. "Updating the Accounts: Global Mortality of the 1918-1920 'Spanish' Influenza Pandemic." Bulletin of the History of Medicine, Spring 2002, 76(1), pp. 105-15.

Jorda, Oscar; Singh, Sanjay R. and Taylor, Alan M. "Longer-Run Economic Consequences of Pandemics." Federal Reserve Bank of San Francisco Working Paper 2020-09, March 2020.

Markel, Howard; Lipman, Harvey B.; Navarro, J. Alexander; Sloan, Alexandra; Michalsen, Joseph R.; Stern, Alexandra Minna and Cetron, Martin S. "Nonpharmaceutical Interventions Implemented by U.S. Cities During the 1918-1919 Influenza Pandemic." Journal of the American Medical Association, 2007, 298(6), pp. 644-54.

Taubenberger, Jeffery K. and Morens, David M. "1918 Influenza: the Mother of All Pandemics." Emerging Infectious Diseases, January 2006, 12(1), pp. 15-22.

Velde, Francois R. "What Happened to the U.S. Economy During the 1918 Influenza Pandemic? A View Through High-Frequency Data." Federal Reserve Bank of Chicago Working Paper 2020-11, April 2020. 